\title{
Confused Customer: Sizing and Styling Related Matters in Online Fashion Shopping in Sri Lanka
}

\author{
Sumith Gopura, Lakmali Kothalawala \\ University of Moratuwa, Katubedda, Moratuwa, Sri Lanka \\ Email: sumithg@uom.lk
}

How to cite this paper: Gopura, S., \& Kothalawala, L. (2021). Confused Customer: Sizing and Styling Related Matters in Online Fashion Shopping in Sri Lanka. Open Journal of Social Sciences, 9, 110-127. https://doi.org/10.4236/jss.2021.99008

Received: July 29, 2021

Accepted: August 30, 2021

Published: September 2, 2021

Copyright $\odot 2021$ by author(s) and Scientific Research Publishing Inc. This work is licensed under the Creative Commons Attribution International License (CC BY 4.0).

http://creativecommons.org/licenses/by/4.0/

\section{(c) (i) Open Access}

\begin{abstract}
The increased popularity of online shopping due to easy access, fashion retailers were opting for a different approach to increase their online sales. This study investigates the sizing and styling related matters in online fashion shopping in Sri Lanka. The study has taken a qualitative approach through a comparative content analysis of Sri Lankan and international fashion shopping websites selected from purposive sampling, and an inductive reasoning of fashion consumer survey of Sri Lanka, conducted among hundred participants who have been recruited in a mixed method approach of purposive and random sampling. The results of web content analysis highlight standard sizing and styling related indicators in fashion shopping websites and essential sizing related key indicators to be added to Sri Lankan fashion websites. The consumer survey identifies size and quality of product as key for conventional shoppers in making purchasing decisions. The study concludes the lack of such vital information in fashion shopping websites result in detaching consumers from online shopping in Sri Lanka. The study identifies web contents and presentations to attract more consumers, especially amidst the impact of Covid19 pandemic in fashion retails. The findings are valuable for the countries sharing similar attributes in online fashion retailing globally.
\end{abstract}

\section{Keywords}

Online Shopping, Conventional Shopping, Visual Merchandising, Fashion Consumer, Decision Making, Styling and Sizing, Sri Lanka

\section{Introduction}

Conventional or in-store shopping and online shopping are the main two kinds of shopping among contemporary consumers yet globally, online shopping has 
become significant due to the rise of online access. Consumers can easily purchase many products online with price and quality comparisons saving their time that they would otherwise spend on travel, queuing in conventional shopping (Hasan, 2016; Tirumalareddy \& Kolukisaoglu, 2010). Decision making in conventional shopping is more traditional than in online shopping, however brands which are having strong offline presence are conspicuous on brand loyalty in online (Danaher, Wilson, \& Davis, 2003). Particular to online fashion shopping, there are many factors that consumers must consider in decision making as the product is not experienced by the time they buy, two such vital factors being the size and styling related information. The study mainly focuses on the Sri Lankan online fashion retailing. As the study noticed, many international fashion shopping websites provide product specific information for consumers thus stimulating shopping. Being a developing country, Sri Lankan (SL) online fashion businesses are evolving through international exposure. The new designers and fashion businesses are attentive to their online appearance in various means from social networking to ecommerce.

In this Fashion Industry Investigative Study, we seek the SL consumer perceptions on online fashion shopping through a consumer survey. Align to that, two main factors of decision making in online fashion shopping, the styling and sizing related information in SL fashion websites were also investigated through a web content of selected international and SL fashion Websites in a qualitative approach. The study has taken, mixed method of recruiting online questionnaire survey participants'-primary participants through purposive sampling and then the secondary participants in snowballing, allowing primary participants to make wishful decisions of recruiting participants for the study therefore the researcher expected minimizing the researchers' biases to the study. The web content analysis was chiefly driven by the SL and international fashion websites selected from purposive sampling. This study is significant due to two chief reasons, 1) the original contribution made in investigating online fashion shopping in SL consumer perspectives, 2) investigating the web content of SL online fashion retailers in Sri Lankan in comparison to international fashion websites. In understanding the existing concepts behind the consumer perceptions in traditional and online shopping, below in-depth literature review was conducted on the factors affecting the shopping behaviors, the visual merchandising in fashion purchasing, the role of product image in online shopping, and the sizing matters and tactile sensation in fashion shopping.

\section{Literature Review}

\section{Factors affecting the shopping behaviors}

The online customers' decision making on purchasing depends on the information featured on shopping websites as that the only method of interaction they get. Often, easier understanding is better in decision making for consumers. Therefore, the importance of product information (sizing, styling), the quality 
(fabric, stitching, finishing), user interface design (friendliness of website) and service information (delivery and return policy etc.) in the online shopping are very high as highlighted by Park and Kim (2003) for better consumer attraction. As Bellman, Lohse and Johnson (1999) indicate, in online shopping the website should be more convenient to surf product and buy with easier check out, repeat-purchases if required, providing the relevant information for making purchasing decisions. However, the gender of the customer is a more influential factor in shopping and a motivator than age, education, and occupation as Roy Dholakia (1999) highlights.

In general, consumer variables such as age, environmental deposition, self-regulation and task-orientation, and situational variables such as purchase risk and time pressure are effective on setting emotion, cognition and behaviors of customers therefore matter in setting consumer moods in purchasing (Lam, 2001). In this study, consumer perceptions as well as information featured on shopping websites are considered in investigating sizing and styling related issues in online fashion shopping among female consumers in SL.

\section{Visual merchandising in fashion purchasing}

In the retail business, Visual Merchandising (VM) has been used as a tool of attracting the customers. As Gudonavičienè and Alijošienè (2015) highlight, customer mood in purchasing is motivated by five VM elements: window display, in-store design, promotional signage, store layout and store atmosphere. As Bhatti and Latif (2014) also confirm, the customer attraction by the look of the shop, promotions, sign boards, atmosphere, section divisions, shelf arrangement, and cleanliness are the other key factors that increase the unintended purchasing. In particular to women's apparel buying behaviors, motivation, perception and lifestyle works as influencing factors (Jain, Sharma, \& Narwal, 2012).

As the conventional shopping shifted to online, the features and elements of VM of conventional shopping have also been influencing the online shopping with modifications such as sitemap, search engines, and various means of merchandise category and presentation methods. The ability to fit-on in conventional shopping is the key in making purchasing decisions, however online customers can only choose the garment browsing the visual and technical details given through virtual VM techniques: enlarge, rotate, and see it in different colours, views etc. (Ha, Kwon, \& Lennon, 2007). Therefore, the conventional shopping has an advantage in comparison to the online shopping to meet many key consumer requirements. On the other hand, the online consumers find it comfortable to shop given the details on the web and make decisions only using the virtual information. How far a virtual VM can represent the actual garment is important in this process.

\section{The role of the product image in online shopping}

In online shopping, the most important factor is the "image" through which the customers are able to understand the product as they cannot touch and feel. Therefore, the methods of visualizing product quality, key details, and colours in 
online shopping are vital. Nonetheless, high quality virtual platforms with quality visuals and textual information improve the value of products. As Cano, Perry, Ashman and Waite (2017) state the product image can have an impact on user search behavior and is a potential factor that enhances the brand value and brand loyalty in online shopping. The brand image is often maintained by advertising and award-winning marketing funds as Wang and Tsai (2014) highlight. The product image is the similitude of the whole brand that consists of brand values and strategies and mainly depends on perceived quality of products. Therefore, product "image" holds a significant position in online shopping.

\section{Sizing matters fashion shopping}

Sizing in fashion shopping has two perspectives, one is the size of the outfit, two is the size of the body. Size can also be related to the image of an individual in which we take consideration of mental representation of the body image (Kim, 2008). The culture always sets standards for this. When a garment does not fit properly, the customer feels a higher discrepancy of their body. In apparel shopping, "fit" or the size of the garment is one of the most important factors and the consumers risk their purchases when they buy online adhering only to the visual and technical information available on websites. In order to overcome this, the online retailers use many features including technological advancements with innovative VM techniques such as 3D-images, virtual models, and digital images with zooming features. In online buying, making purchasing decisions based on the look and the fit is an imaginary process (Kim, 2008). However, a best fitted garment for an individual customer is the best satisfaction as psychological comfort plays an important role. Therefore, in absence of real time fit-on, fashion shopping websites must consider customers' psychological comfort on virtual fiton for better attraction.

\section{Touch and feel in fashion shopping}

Touch and feel (tactile sensation) the garments is one of the key attributes in conventional shopping that makes the customer confident in purchasing. The comfort factor of the garment is mainly decided by the consumer through touch and feel sensation. Many technological advancements have been introduced to match the real-life tactile sensation in online shopping, part of which is the images and words that are used in online websites through appearance representative evaluation words and tactile sensation representative evaluation words (Ishikawa, Nakamori, Sasaki, Miyatake, \& Ayama, 2014). That allows consumers to see and read feelings associated with touch and feel sensation and relate them with their previous experience and therefore make decisions. As Rodrigues, Silva and Duarte (2017) indicate the textual haptic information also increases the perception about the garment and enhances the purchasing intention of online shopping, making the product to be more real. Further, in realization of tactile sensation in online platforms, a method of image presentation through light transmittance by evaluating the texture and the physical property of the actual fabric is used thus exhibiting the thinness and thickness of a fabric (Ishikawa, Taira, Sasaki, Miyatake, \& Ayama, 2015). Goswami, Chittar and Sung (2011) also high- 
light that when browsing fashion apparel online, the product rotation and touchrelated features such as fabric scrunch can create an immersive shopping experience that overcomes the needs for physical touch. As such, keeping up with the mainstream technological trends is vital for better customer experience in online shopping as indicated by Jang, Hur and Choo (2019).

\section{Methods}

In this study, a qualitative approach is used in investigating the sizing and styling related issues of online fashion shopping in SL. Initially, to get a deep understanding about those issues and set the grounds, a comparative "Content Analysis" method was used on international and SL fashion shopping websites. Next, an online questionnaire survey was used in obtaining consumer perceptions regarding online shopping. This section discusses the specific approaches taken in identification, selection of local and international websites, and recruiting participants for data collection, and analysis of the study.

\section{Data collection}

\section{Fashion Web content}

Ten Sri Lankan and ten international fashion shopping websites (Table 1) were selected from purposive samplings, which include four from the UK, three from the US, and three from Japan. Popularity of the brands in online fashion retailing and similarity of product categories sold were the main considerations in selecting brands. Given the time frame of this study being a part of the fashion industry investigative study of the second author's bachelor degree and the sample sizing of similar studies, the number of websites were limited to ten (Strebinger \& Rusetski, 2016). Those websites were studied based on the visual and technical information provided for consumers on their merchandise, using screenshots captured during the process. Their presentation techniques were also considered taking into account the newest fashion collections on the website.

Table 1. Selected fashion websites.

\begin{tabular}{|c|c|c|c|c|c|}
\hline \multirow{2}{*}{ Brand } & \multirow{2}{*}{ Sri Lanka } & \multirow{2}{*}{ Brand } & \multicolumn{3}{|c|}{ International } \\
\hline & & & UK & US & Jap. \\
\hline B1 & $\mathrm{X}$ & B11 & $\mathrm{X}$ & & \\
\hline B2 & $\mathrm{X}$ & B12 & $\mathrm{X}$ & & \\
\hline B3 & $\mathrm{X}$ & B13 & $\mathrm{X}$ & & \\
\hline B4 & $\mathrm{X}$ & B14 & $\mathrm{X}$ & & \\
\hline B5 & $\mathrm{X}$ & B15 & & $\mathrm{X}$ & \\
\hline B6 & $\mathrm{X}$ & B16 & & $\mathrm{X}$ & \\
\hline B7 & $\mathrm{X}$ & B17 & & $\mathrm{X}$ & \\
\hline B8 & $\mathrm{X}$ & B18 & & & $\mathrm{X}$ \\
\hline B9 & $\mathrm{X}$ & B19 & & & $\mathrm{X}$ \\
\hline B10 & $\mathrm{X}$ & B20 & & & $\mathrm{X}$ \\
\hline
\end{tabular}




\section{Questionnaire survey}

An online questionnaire was logically developed to be built upon each question considering the objective of the study: obtaining the consumer perceptions of shopping from the participants through participants demography, access to fashion, shopping behavior, fashion taste. The questionnaire was consisted of three directions-Online shopping, Conventional shopping, and Search online and buy from the retail outlets. However, each participant was able to select only one direction and answer ten questions within that direction in which eight multiple choice questions and two questions for short answers were included. There were four demographic questions and six personalized questions composed in one direction that investigated their fashion taste, shopping experience, and Brand consciousness.

\section{Participants}

Initially, 30 primary participants were identified and selected in purposive sampling as in Figure 1 (Ritchie, Lewis, Nicholls, \& Ormston, 2013). Only female fashion consumers were selected in this stage that included ten students, ten government sector and ten private sector employees. Thereby balance the participants professional orientation. The selection of the participants was chiefly based on the researchers personal and professional network, yet no special attention was paid on participants fashion taste, shopping experience, and brand consciousness which are investigative factors of the study therefore the researcher expected no biases created by the selection to the study results. Participants' age category was also not considered on selection. An email with the link to the online questionnaire form was sent to initial participants. In completion of answering the questionnaire, they were requested to forward the link to at least five of their female colleagues who would fit into the framework of the study

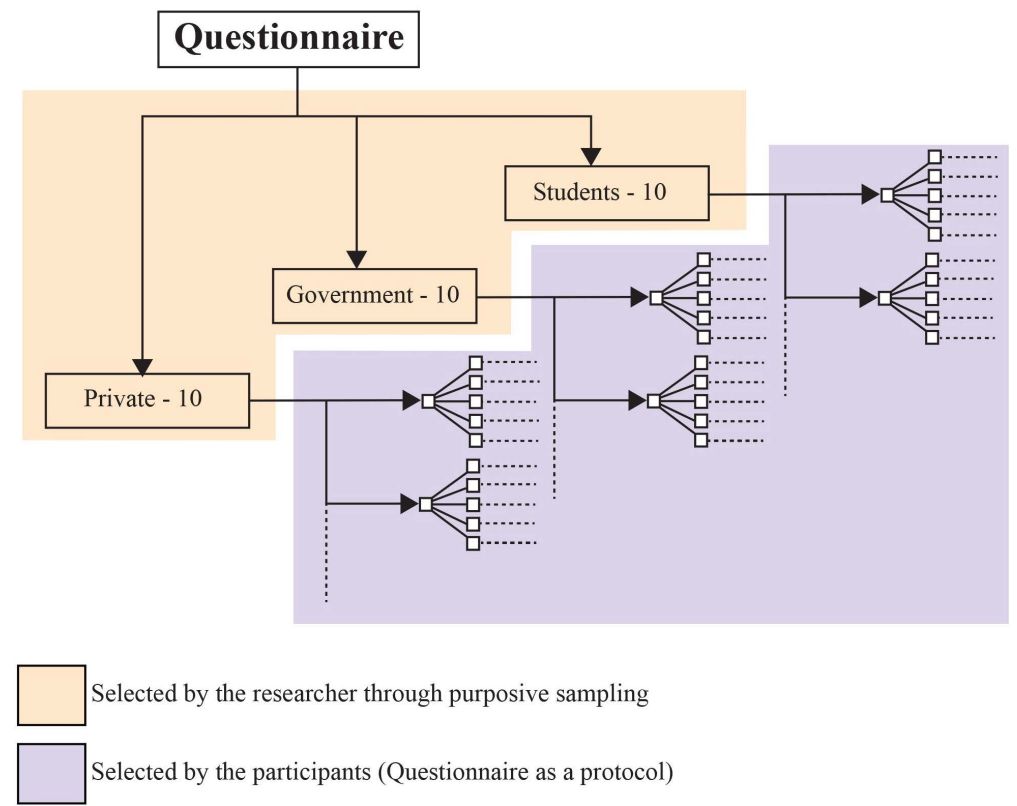

Figure 1. Participant recruitment (Developed by authors). 
based on the questionnaire. Thus, the secondary participants were randomly employed during the data collection process. Total number of participants was limited to hundred by stopping the reception of the responses given the time constraints of the study. An automated message was sent for those who were trying to respond thereafter for the courtesy of attempting following the ethics of the study.

\section{Data Analysis}

The study mainly employed a qualitative approach in its analysis that built upon comparative "Content Analysis" and using inductive reasoning as required for the questionnaire survey data analysis as in Figure 2.

In order to conduct web content analysis a general framework of fashion shopping web content (Figure 3) was developed considering the sizing and styling features depicted in international fashion shopping websites. Twenty purposely selected fashion shopping websites were used in developing this framework, considering the styling and sizing related visual and technical features. Through the general framework of fashion shopping web content, the styling and sizing related indicators in selected international and SL fashion shopping websites were analyzed and the gaps in SL web contents were highlighted comparatively. The data gathered through the online questionnaire were subjected to inductive reasoning in a qualitative approach without considering the quantitative aspect of the data. The conclusions of the study were then derived in a summative approach to the findings from both data analysis.

\section{Ethical statement}

This study has used an ethical approach in its design and conduct-selection of fashion shopping websites and questionnaire survey participants, collection of

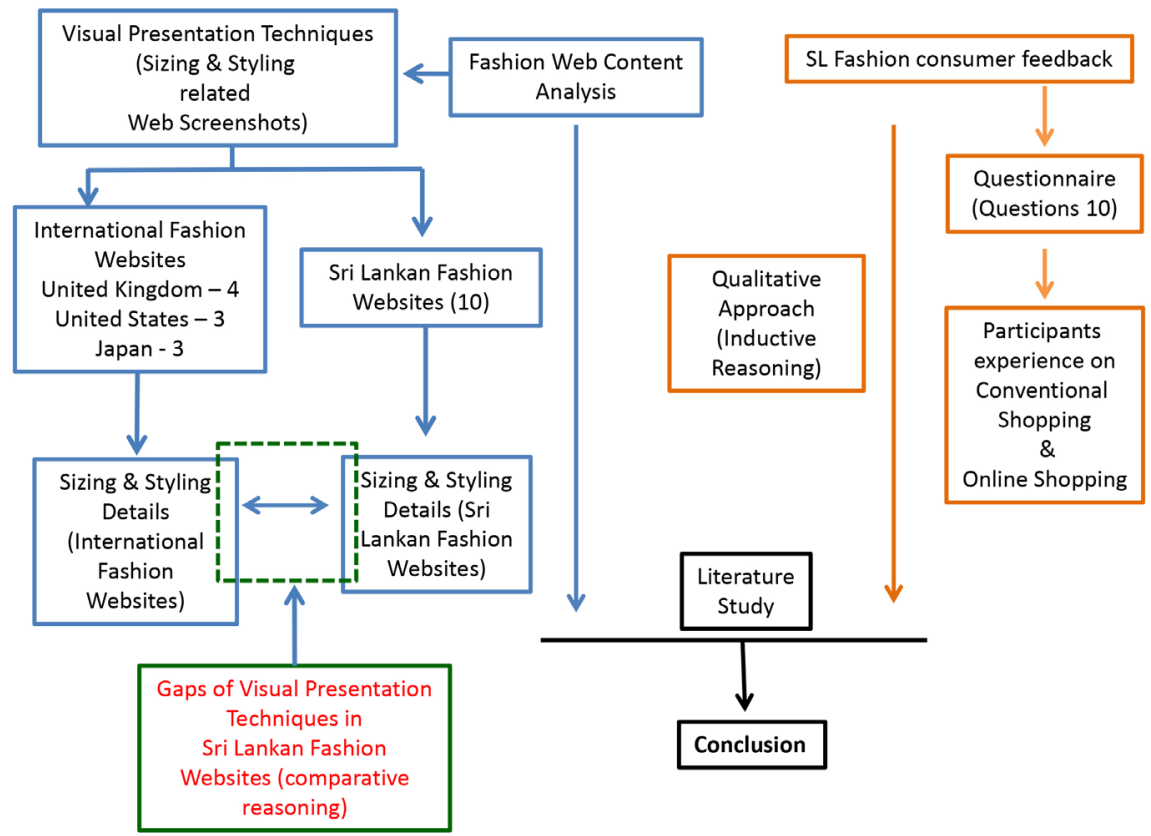

Figure 2. Data analysis (Developed by authors). 


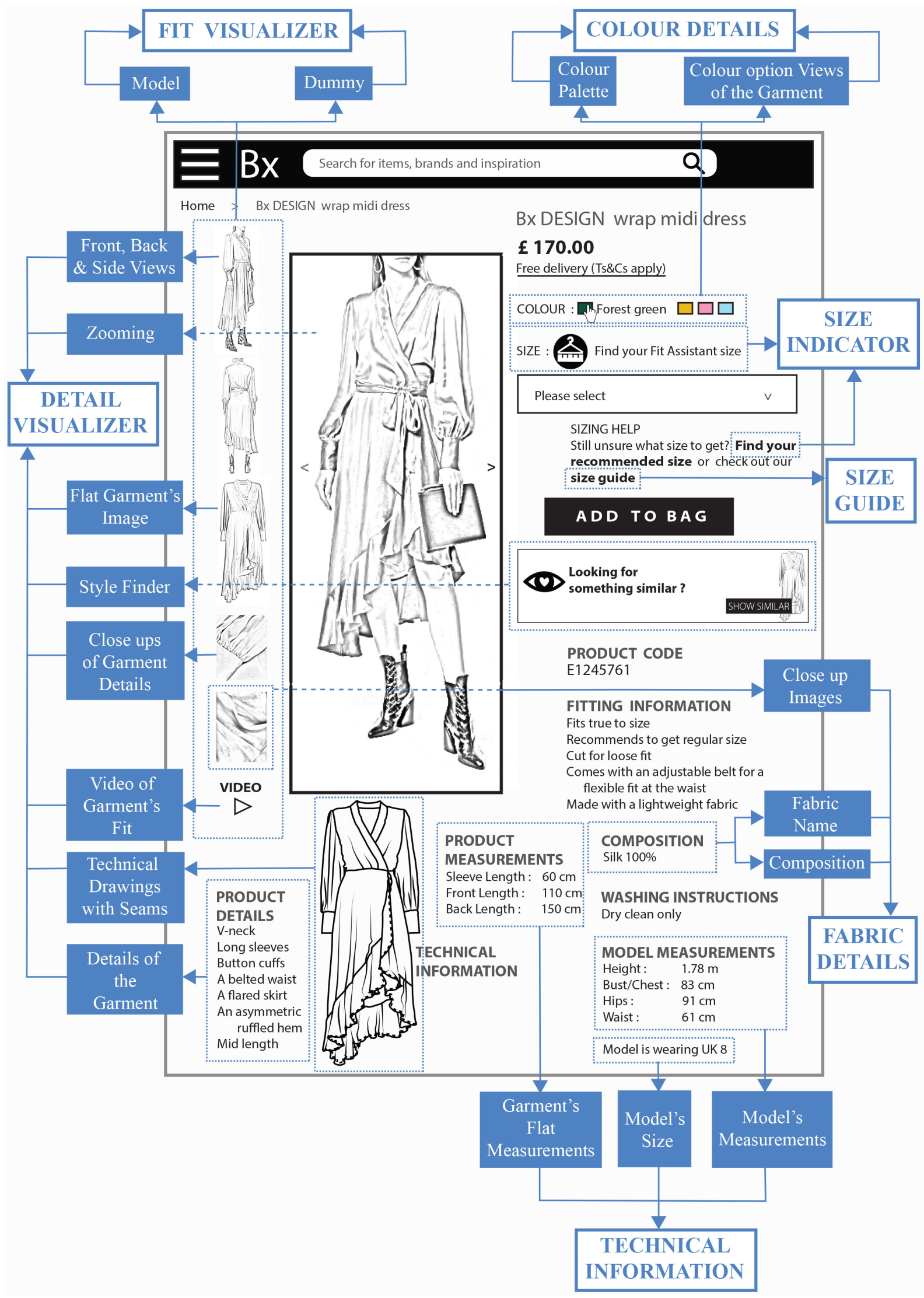

Figure 3. Web content analysis framework (Developed by authors). 
data, analysis of data, representation and dissemination of study findings. Access to open source fashion shopping web content data did not require prior consent from the fashion shopping websites (Brands). However, confidentiality and anonymity of their commercially sensitive data were protected during the analysis and dissemination of study findings. During the questionnaire survey, the identification and recruitment of primary participants were done through mails sent with the link to the online questionnaire form mentioning the study design and ethical considerations. The random sample of secondary participants was informed through primary participants. We have obtained ethical clearance for this study (Ethics Declaration Number EDN/2020/006) and made sure all general and specific research ethics were followed during this study. The anonymity of all identifiable data, and the confidentiality of personally and commercially sensitive data were protected through applying either code names or removing the data as necessary.

\section{Results and Discussion}

In this section, the data gathered through web content and the online questionnaire are analyzed and discussed through the above-mentioned qualitative approach. First, the web contents analysis discusses the international and SL fashion shopping websites contents in comparison to the general framework of fashion shopping web content (Figure 3), using styling and sizing features while the data of the consumer survey is inductively analyzed and merged with the web content analysis thereafter.

\section{Online fashion shopping web content analysis}

The figures below were developed through a comparative analysis of the web contents of the selected international and SL fashion shopping websites against the general framework of fashion shopping web content.

\section{International fashion shopping web content. sizing indicators}

As indicated in Figure 4, fit visualizer, size guides, size indicator and technical information are the key sizing related information identified in the web contents of selected international fashion shopping websites. Providing sizing information for consumers, each offered visually connected in-detail explanations therefore customers are exposed to the product image, while they are concerned about the body image. It provides better understanding for consumers in shopping fashion online.

\section{SL fashion shopping web content. sizing indicators}

According to Figure 5, Fit visualizer, size guides, and technical information are key sizing related information identified in the SL fashion shopping websites, however those were not offering in-depth visually connected details in comparison to above international fashion shopping websites (Figure 3 and Figure 4). The size indicators were also not seen in the selected websites for this study therefore customers are lacking in exposure to the product image as well as the body image. 


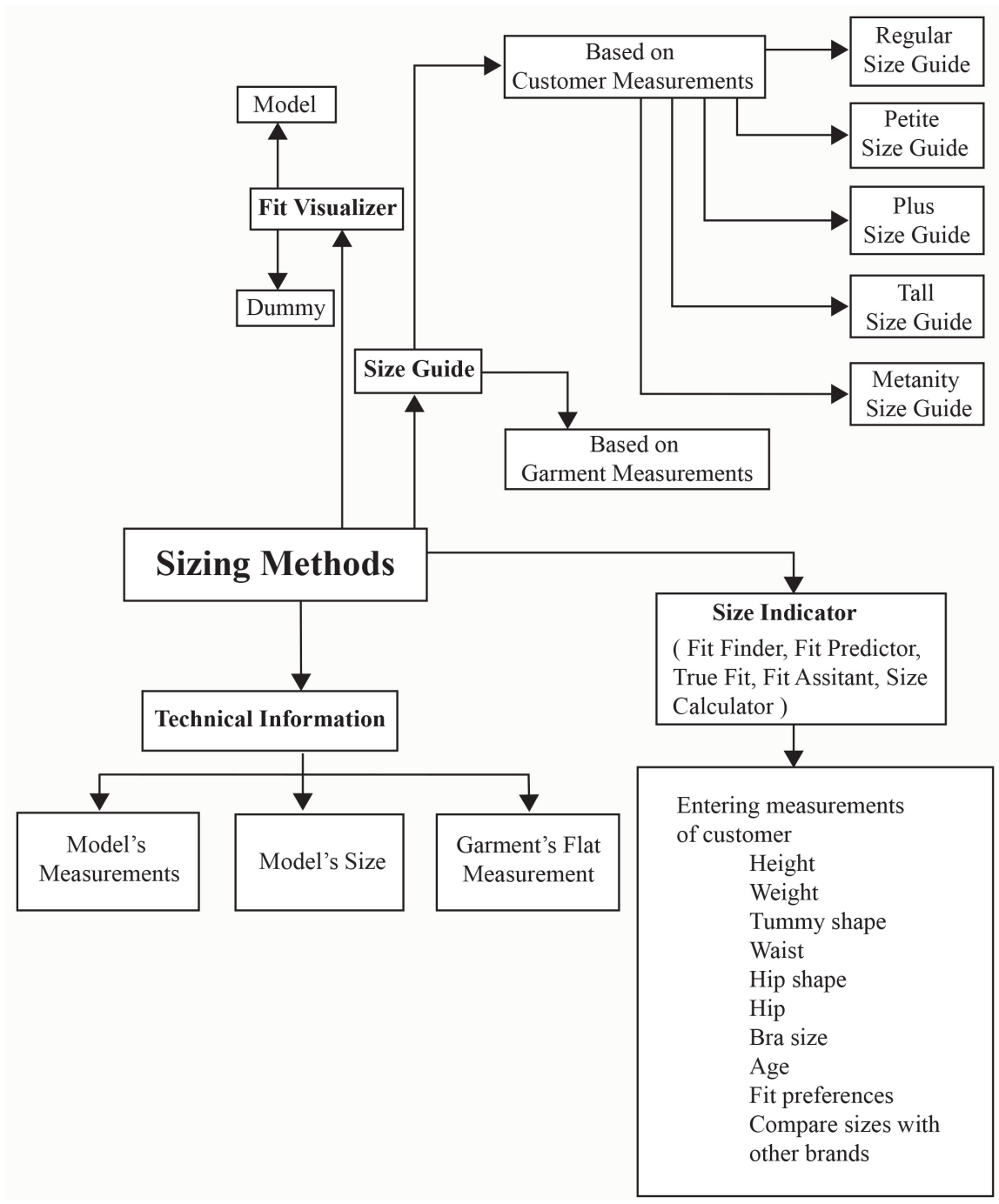

Figure 4. Sizing indicators of international fashion shopping websites (Developed by authors).

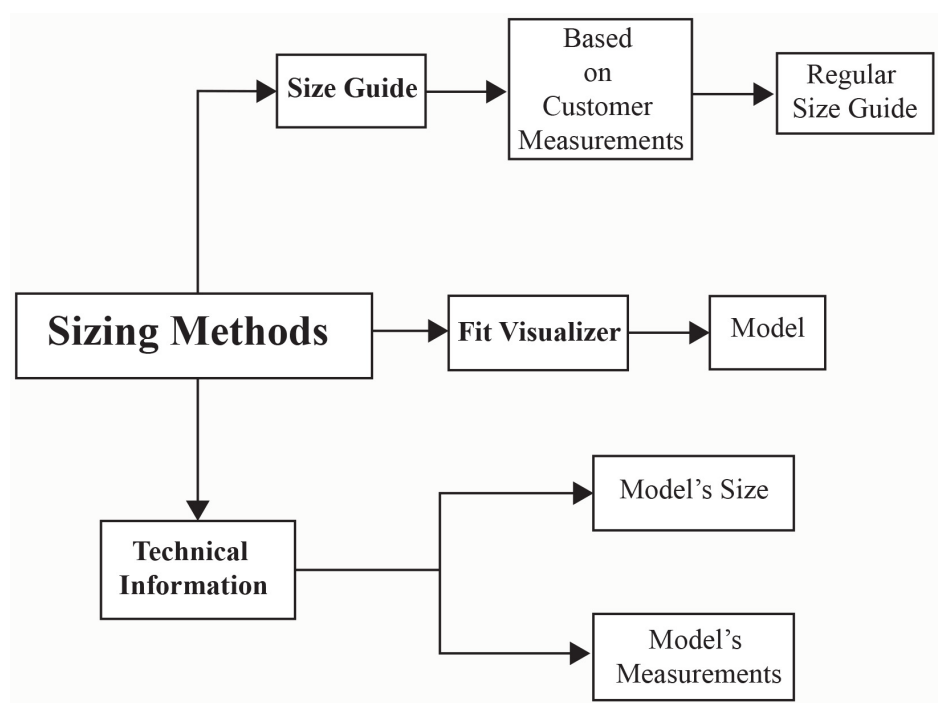

Figure 5. Sizing indicators of SL fashion shopping websites (Developed by authors). 
Comparison of international and SL fashion shopping websites sizing indicators reveals that there are rooms for improvement in SL online fashion shopping web contents in relation to sizing as indicated in Figure 6 below. Mainly the features such as fit visualizer (Dummy), size guide based on customer measurements (Plus, Petite, Tall and Maternity), size guide based on garment measurements, technical information (garment flat measurements) and size indicators are not available in SL fashion shopping websites. These features are very important in understanding product image therefore consumers can minimize the discrepancy of their body image that makes the online purchases right fit for consumers.

\section{International fashion shopping web content: styling indicators}

As in Figure 7 the fabric details such as fabric name, composition, close-up images of fabric, colour details, and detailed visualizer which included zooming,

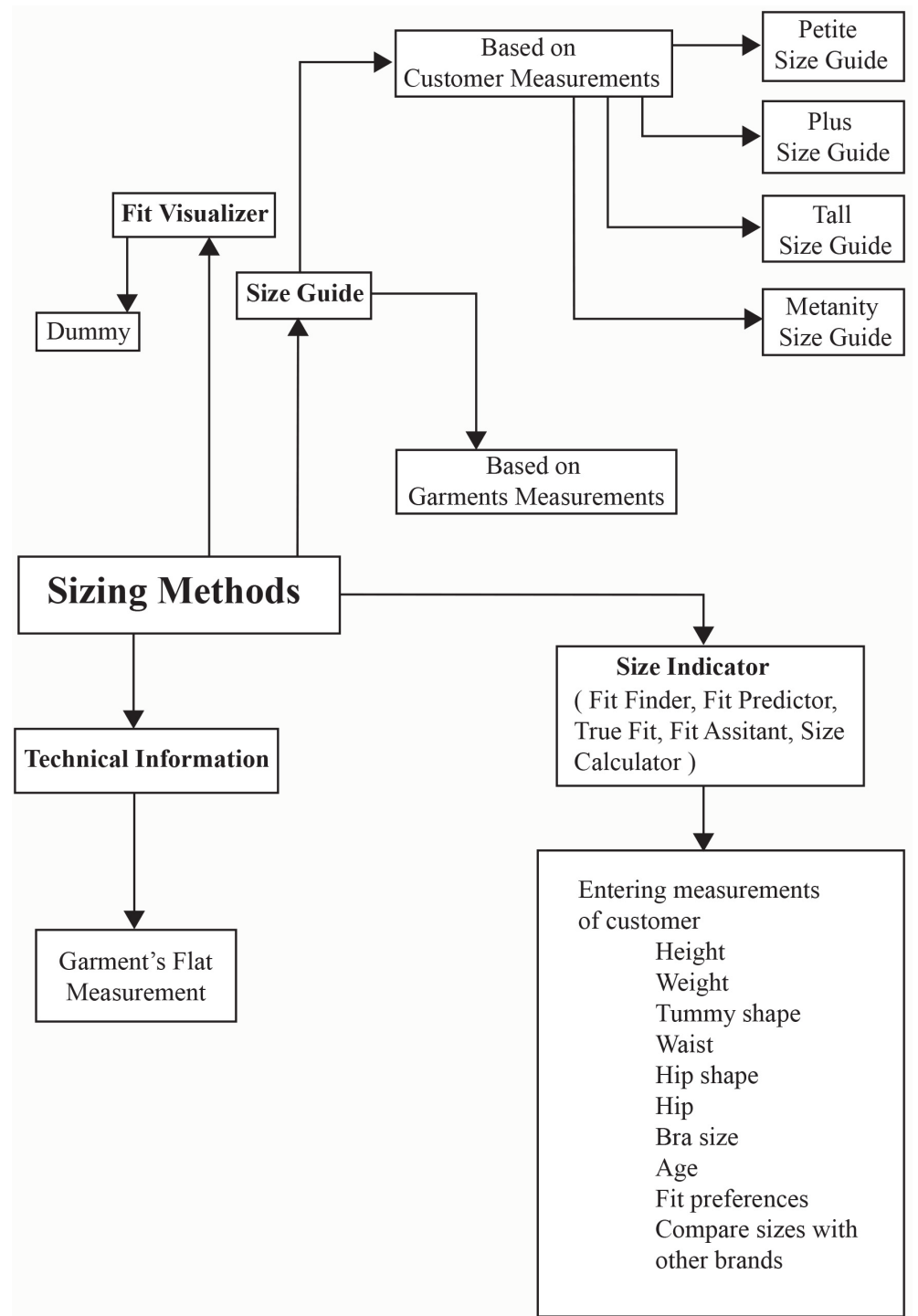

Figure 6. Sizing indicators not available in SL fashion shopping websites (Developed by authors). 


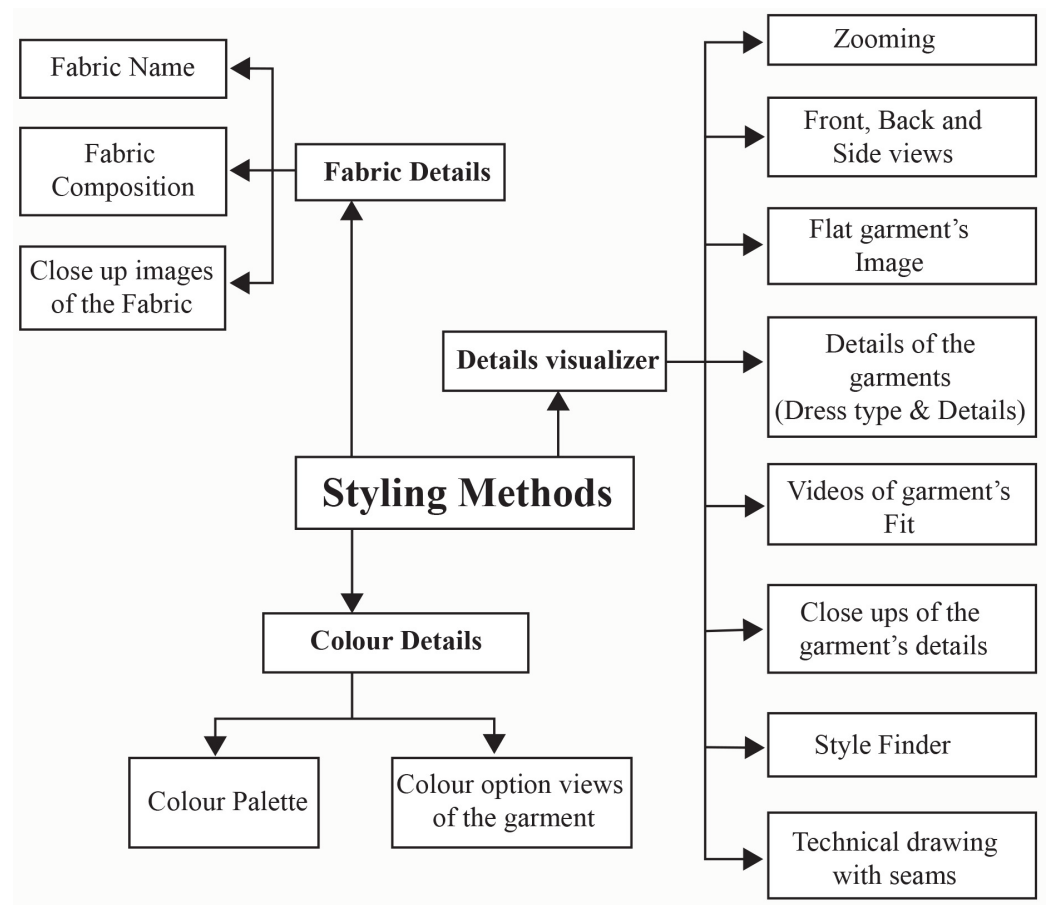

Figure 7. Styling indicators of international fashion shopping websites (Developed by authors).

views from different angles including close-up details of the garment, videos, style finders that display similar garments according to the consumer choices and technical drawings are used in indicating styling related information in selected international fashion shopping websites. These indicators include appearance and tactile sensation representative evaluations, most of which are able to enhance consumer shopping experience in online fashion shopping platforms.

$S L$ fashion shopping web content. styling indicators

The selected SL online fashion shopping platforms also consist of (Figure 8) fabric details, colour details, and detailed visualizers, however with limited optimizing capabilities. Comparison of selected international and SL fashion shopping websites' styling methods indicate that there are opportunities for SL online fashion shopping platforms styling methods to be improved as in Figure 9 below.

Mainly the features such as close-up images of fabric and garment details, flat garment images, fit videos, style finders, technical drawings with seams are not available in SL fashion shopping websites. These features are very important in understanding the appearance and tactile sensation of products that enhance the product image.

In summary, SL fashion shopping websites in comparison to the general framework of fashion shopping web content has room for improvement in both sizing and styling related features.

Online questionnaire survey data analysis

The analysis of questionnaire survey data is based on inductive reasoning and the findings indicated below with reflections. Given the data, a higher number of 


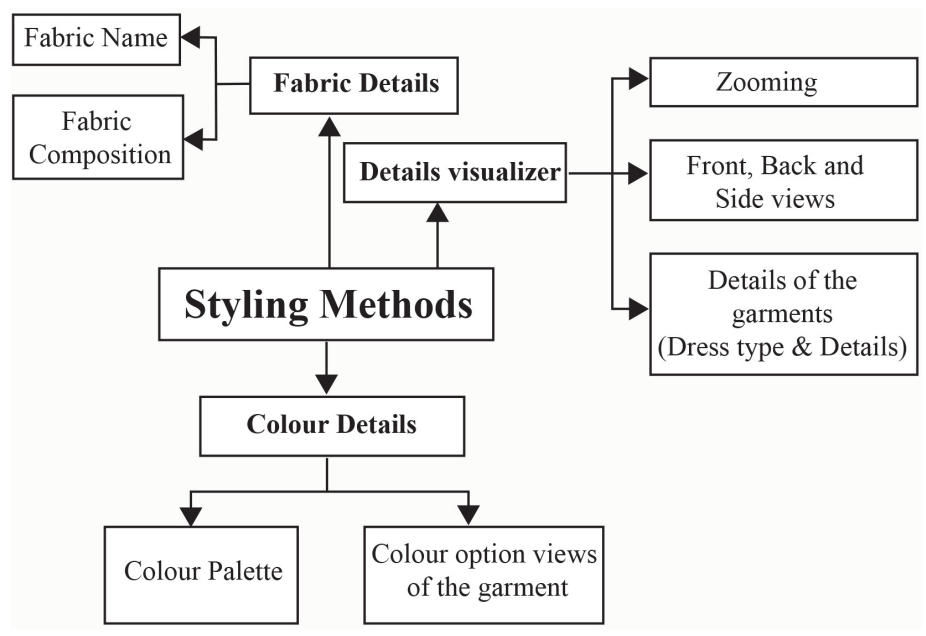

Figure 8. Styling indicators of SL fashion shopping websites (Developed by authors).

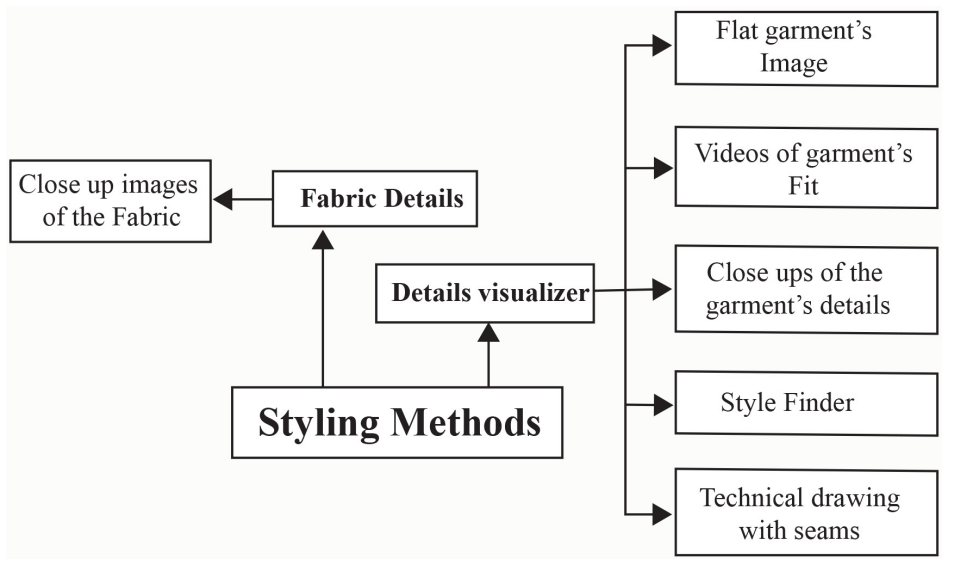

Figure 9. Styling indicators not available in SL fashion shopping websites (Developed by authors).

employed participants responded to the study as a combination of government and private sector employees. Majority of participants were in the age category of $18-29$. This could be considered as the fashion active age group in the study population.

\section{Considerations in purchasing garments}

As SL fashion consumer survey findings highlight, the majority of the study participants are fashion-conscious and, in a fashion active age group. A higher number of participants considered fashionable factors such as trends, key styling and colour when they purchase garments yet less in consideration on the functional aspects such as occasional wear, work wear and sportswear and value additional aspects such as prints, embroidery and embellishments of fashion products in their fashion purchase. It indicates that taking attention of these consumers requires styling details to be highlighted in SL online fashion websites with the styling indicators that are not available in SL fashion shopping websites as results of the study identified in Figure 9.

Participants' mode and mood of purchasing garments 
According to the responses of SL fashion consumer survey, the consumers are mainly into conventional shopping for their fashion needs and increasingly a large number of consumers are moving into online search for fashion products from which more consumers are into search online and buying from the retail outlets. This indicates that they are not confident enough to make purchasing decisions only from online browsing. The participants who chose online shopping for their fashion purchase revealed that the time taken in in-store shopping has been the major reason for them opting shopping online. Other factors such as $24 \times 7$ availability, easy payment methods and access through mobile phones are the key drivers which have prompted them to shop online. The satisfaction of consumers on SL fashion shopping websites after services, Delivery and return policies, was considerably high among the majority of respondents reasoning the satisfactory delivery, however they highlighted the fact of less product quality in general in online shopping. Online fashion businesses should focus more on the consumer segments who are not confident enough to make purchasing decisions only from online browsing as identified in the study.

Majority of conventional shoppers appreciated fit-on purchasing, touch, feel and observe exact colours of the garment through their shopping experience. Their decision of choosing different fashion retailers is based on previous experience, the store location, VM and most importantly the friendliness of the staff. Nonetheless, emotional pleasure of owning the product immediately after purchase was one other fine consideration of the respondents who appreciated instore purchasing. The feeling of owning on purchase gives a psychological comfort for consumers and is a very important consideration to be made available in the case of online shopping. This could be done in many ways: arranging fast delivery to reduce consumer waiting time, arranging purchase loyalty tokens (this could be a customized token of appreciation to purchase) that can be sent to consumers through e-mail or mobile app which gives the feeling of owning the product until it is received by them. Enhancing the tactile sensation features of the garments available on fashion websites are also very crucial for SL online fashion brands to consider while attracting the majority of conventional shoppers who appreciated touch and feel of the garment through their shopping experience.

Observing the difference between virtual fit and actual fit, being unable to touch and feel the garment before making the purchasing decision are the key reasons for searching online and buying in-store as highlighted by the participants. These consumers have also been fond of easy and quick comparison of the fashion products and finalize purchases before visiting the store. However, the lack of information and limited featuring of some of the qualities of garments in SL fashion shopping websites have been the major concerns of the participants.

As the findings of the study indicate, SL consumers select fashion shopping websites based on four reasons: having satisfied with the sizing indicators, previous experience, customer reviews, and user-friendliness of the website. Parallelly, garment's sizing information, fabric and colour details are the key concerns 
of consumers before buying online which are in most of the cases provided by the SL online fashion shopping websites.

Most preferred fashion web buying website

Based on the responses, the participants' preferred SL fashion buying website is B5. The majority of in-store shoppers are also aware of $\mathrm{B} 5$, and their online store has given the opportunity for in-store shoppers to search online and buy from the retail outlet. Figure 10 below highlights the web content of B5.

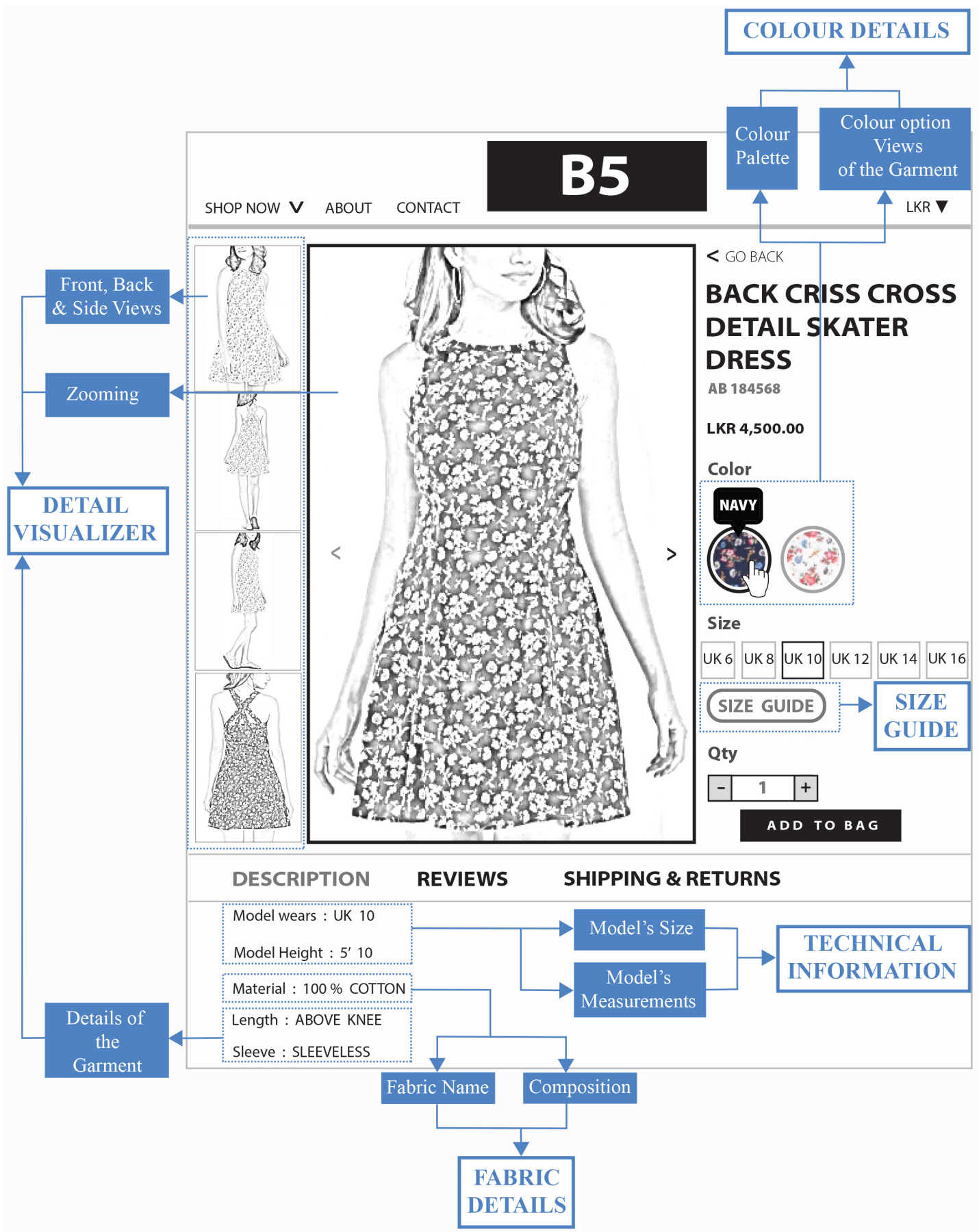

Figure 10. Web contents of B5 (Developed by authors). 
As indicated in Figure 11, B5 has styling and sizing related visualizers, however, lacks in fit visualizer (Dummy), size guide based on customer measurements (Plus, Petite, Tall and Maternity), size guide based on garment's measurements, technical information (garment's flat measurements) and size indicators in comparison to Figure 3.

\section{Cross comparison of web content analysis and questionnaire survey}

As in content analysis, fit visualizer-using dummy, size guides with measurements, size indicators help finding the customers' size after entering their measurements, and technical information such as garment's flat measurements are not seen in SL fashion websites. Nonetheless, the fabric detail with close up images, and detail visualizer that includes the flat garments' images, close ups of the garment details, videos, style finders that find similar garments and the technical drawings were not available in SL fashion websites. The conventional in-store shoppers expect these features from online shopping. As per the questionnaire responses, shopping experiences through the quality of product such as finishing, colour and the material which are lacking in expression in the case of online have held the consumers in conventional shopping. The limited information about sizing is the main reason for their detachment from online shopping in this context.

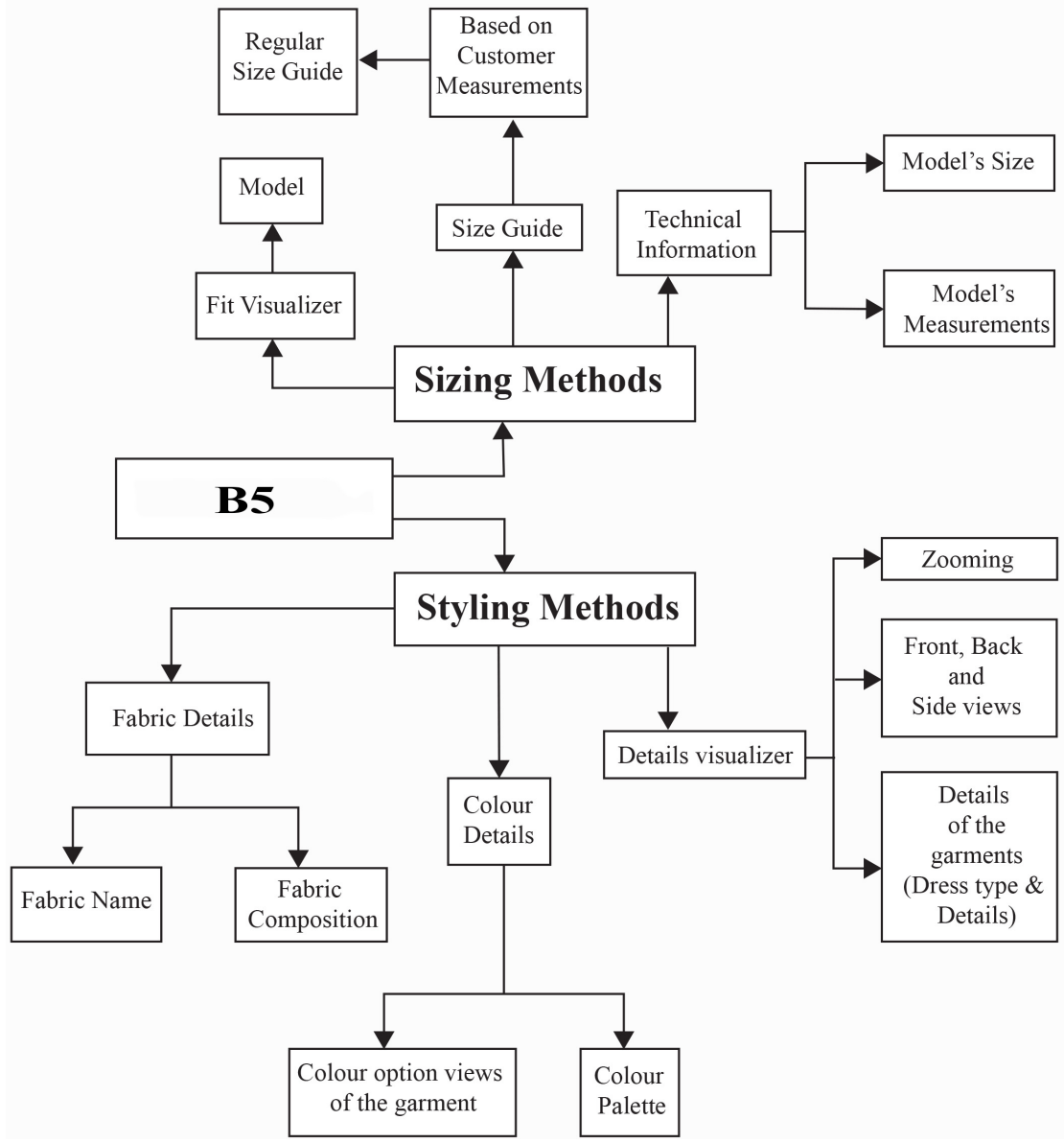

Figure 11. Sizing and styling methods of B5 (Developed by authors). 


\section{Conclusion and Implication}

Majority of the study population from SL are fashion active, mainly considered trends, styling and colour rather than functional and value additional aspects. In this study, the consumers are highly driven by the factors of sizing and quality of the product such as finishing, colour and the material which are currently lacking in the interpretation of online fashion websites. The experience provided in conventional in-store shopping on location, $\mathrm{VM}$, and friendliness of the staff are the key consumer attractions while the ability to fit on purchasing, touch and hand feel of the fabric, and colours are other influential factors. According to the study, increasingly a large number of consumers are inspired by online search and buying from the retail outlets chiefly based on the fact that they are not confident enough to make buying decisions only online. Using online shopping is due to the time saving, easy access to shopping and payment methods as results indicated. Further, the sizing methods, fabric and colour details, customer reviews and the user friendliness of the websites were motivators for them to shop online. One in particular, Brand B5 has been the most popular brand among online shoppers in SL. As the results of the study affirmed that there are many features that are not available in the SL fashion websites which are also vital in attracting more consumers. These findings are timely significant for online fashion businesses in improving their web content to attract more consumers providing better customer experience, especially under this Covid19 impact. This study was limited by time and therefore the number of Websites selected and the Questionnaire survey participants had to be limited. However, the findings of this study are also valuable for the countries sharing similar attributes in online fashion retailing globally. Further studies are recommended on web content development based on the findings of this study, particularly for Sri Lankan online fashion brands.

\section{Conflicts of Interest}

The authors declare no conflicts of interest regarding the publication of this paper.

\section{References}

Bellman, S., Lohse, G. L., \& Johnson, E. J. (1999). Predictors of Online Buying Behavior. Communications of the ACM, 42, 32-38. https://doi.org/10.1145/322796.322805

Bhatti, K. L., \& Latif, S. (2014). The Impact of Visual Merchandising on Consumer Impulse Buying Behavior. Eurasian Journal of Business and Management, 2, 24-35.

Cano, M. B., Perry, P., Ashman, R., \& Waite, K. (2017). The Influence of Image Interactivity upon User Engagement When Using Mobile Touch Screens. Computers in Human Behavior, 77, 406-412. https://doi.org/10.1016/j.chb.2017.03.042

Danaher, P. J., Wilson, I. W., \& Davis, R. A. (2003). A Comparison of Online and Offline Consumer Brand Loyalty. Marketing Science, 22, 461-476.

https://doi.org/10.1287/mksc.22.4.461.24907

Goswami, A., Chittar, N., \& Sung, C. H. (2011, March). A Study on the Impact of Product Images on User Clicks for Online Shopping. Proceedings of the 20th International Conference Companion on World Wide Web, Hyderabad, 28 March 2011-1 April 2011, 45- 


\section{6. https://doi.org/10.1145/1963192.1963216}

Gudonavičienė, R., \& Alijošienè, S. (2015). Visual Merchandising Impact on Impulse Buying Behaviour. Procedia-Social and Behavioral Sciences, 213, 635-640.

https://doi.org/10.1016/j.sbspro.2015.11.464

Ha, Y., Kwon, W. S., \& Lennon, S. J. (2007). Online Visual Merchandising (VMD) of Apparel Web Sites. Journal of Fashion Marketing and Management, 11, 477-493. https://doi.org/10.1108/13612020710824553

Hasan, B. (2016). Perceived Irritation in Online Shopping: The Impact of Website Design Characteristics. Computers in Human Behavior, 54, 224-230. https://doi.org/10.1016/j.chb.2015.07.056

Ishikawa, T., Nakamori, S., Sasaki, K., Miyatake, K., \& Ayama, M. (2014, June). Investigation of Appearance and Tactile Sensation Scales for Evaluating Clothes in Online Shopping. KEER2014: Proceedings of the 5th Kanesi Engineering and Emotion Research, Linköping, 11-13 June 2014, 537-543.

Ishikawa, T., Taira, S., Sasaki, K., Miyatake, K., \& Ayama, M. (2015). A Method for Developing Images of Clothes Based on Visual and Tactile Evaluations of "Thickness" and “Thinness”. Procedia Manufacturing, 3, 2162-2166. https://doi.org/10.1016/j.promfg.2015.07.356

Jain, V., Sharma, A., \& Narwal, P. (2012). Impact of Visual Merchandising on Consumer Behavior towards Women's Apparel. International Journal of Research in Management, 5, 106-117.

Jang, J. Y., Hur, H. J., \& Choo, H. J. (2019). How to Evoke Consumer Approach Intention toward VR Stores? Sequential Mediation through Telepresence and Experiential Value. Fashion and Textiles, 6, Article No. 12. https://doi.org/10.1186/s40691-018-0166-9

Kim, H. (2008). The Impact of Body Image Self-Discrepancy on body Dissatisfaction, Fashion Involvement, Concerns with Fit and Size of Garments, and Loyalty Intentions in Online Apparel Shopping. Doctoral Dissertation, Iowa State University. https://doi.org/10.31274/rtd-180813-16931

Lam, S. Y. (2001). The Effects of Store Environment on Shopping Behaviors: A Critical Review. ACR North American Advances, 28, 190-197.

Park, C. H., \& Kim, Y. G. (2003). Identifying Key Factors Affecting Consumer Purchase Behavior in an Online Shopping Context. International Journal of Retail \& Distribution Management, 31, 16-29. https://doi.org/10.1108/09590550310457818

Ritchie, J., Lewis, J., Nicholls, C. M., \& Ormston, R. (Eds.) (2013). Qualitative Research Practice: A Guide for Social Science Students and Researchers. Sage.

Rodrigues, T., Silva, S. C., \& Duarte, P. (2017). The Value of Textual Haptic Information in Online Clothing Shopping. Journal of Fashion Marketing and Management, 21, 88102. https://doi.org/10.1108/JFMM-02-2016-0018

Roy Dholakia, R. (1999). Going Shopping: Key Determinants of Shopping Behaviors and Motivations. International Journal of Retail \& Distribution Management, 27, 154-165. https://doi.org/10.1108/09590559910268499

Strebinger, A., \& Rusetski, A. (2016). Prioritizing Geo-References: A Content Analysis of the Websites of Leading Global Luxury Fashion Brands. Journal of Global Marketing, 29, 282-297. https://doi.org/10.1080/08911762.2016.1185562

Tirumalareddy, S., \& Kolukisaoglu, H. (2010). Method and System of Providing Recommendations during Online Shopping. U.S. Patent No. US7792706B2.

Wang, Y. H., \& Tsai, C. F. (2014). The Relationship between Brand Image and Purchase Intention: Evidence from Award Winning Mutual Funds. The International Journal of Business and Finance Research, 8, 27-40. 